\title{
Di-Carbon Defects in Annealed Highly Carbon Doped GaAs
}

\author{
J. Wagner \\ Fraunhofer-Institut für Angewandte Festkörperphysik, Tullastrasse 72, D-71908 Freiburg, Federal Republic of Germany \\ R. C. Newman and B. R. Davidson \\ Interdisciplinary Research Centre for Semiconductor Materials, The Blackett Laboratory, \\ Imperial College of Science, Technology and Medicine, London SW7 2BZ, United Kingdom \\ S.P. Westwater, T. J. Bullough, and T. B. Joyce \\ Department of Materials Science and Engineering, The University of Liverpool, L69 3BX, United Kingdom \\ C. D. Latham and R. Jones \\ Department of Physics, University of Exeter, Exeter EX4 4QL, United Kingdom \\ S. Öberg \\ Department of Mathematics, University of Luleå, Luleå, S95187, Sweden
}

(Received 9 July 1996)

\begin{abstract}
Formation of bonded dicarbon $\mathrm{C}-\mathrm{C}$ centers is deduced from the observation of Raman lines at 1742, 1708, and $1674 \mathrm{~cm}^{-1}$ in $\mathrm{GaAs}$ codoped with ${ }^{12} \mathrm{C}$ and ${ }^{13} \mathrm{C}$ after annealing at $850{ }^{\circ} \mathrm{C}$ with concomitant loss of vibrational scattering from $\mathrm{C}_{\mathrm{As}}$. The frequencies agree with results of ab initio theory for a C-C split interstitial (deep donor) formed by the trapping of a mobile interstitial C (displaced $\mathrm{C}_{\mathrm{As}}$ ) atom by an undisplaced $\mathrm{C}_{\mathrm{As}}$ acceptor. Other mechanisms of carrier loss are inferred since a weaker Raman triplet is detected at 1859,1824 , and $1788 \mathrm{~cm}^{-1}$ from a different C-C complex. [S0031-9007(96)01981-3]
\end{abstract}

PACS numbers: 61.72.Vv, 61.72.Ji, 63.20.Pw, 78.30.Fs

Carbon atoms occupying As lattice sites $\left(\mathrm{C}_{\mathrm{As}}\right)$ are the preferred acceptor in GaAs [1] but they have a small covalent radius so that the lattice parameter $\left(a_{0}\right)$ of the as-grown material is smaller than that of undoped GaAs. Annealing highly doped samples $\left(T \sim 850^{\circ} \mathrm{C}\right)$ leads to large reductions in the initial carrier concentration $p_{o}$, [2] and an increase of $a_{0}$ towards that of undoped GaAs. There is no evidence for carbon site switching to produce $C_{\mathrm{Ga}}$ donors [3], and the change in $a_{0}$ is not explained because As and $\mathrm{Ga}$ atoms have similar covalent radii [4]. It was later proposed that the introduction of interstitial hydrogen atoms might play a role [4] since they passivate the $\mathrm{C}_{\mathrm{As}}$ acceptors [3] and the $\mathrm{H}-\mathrm{C}_{\mathrm{As}}$ pairs reduce the lattice contraction [5]. However, highly doped GaAs grown by chemical beam epitaxy (CBE) containing a negligible concentration of hydrogen also shows high temperature instability [6]; this proposal is also clearly incorrect.

A third proposal, the subject of this Letter, is that at elevated temperatures $\mathrm{C}_{\mathrm{As}}$ acceptors jump into interstitial sites. The presence of such $C_{i}$ atoms has been invoked to explain channeling measurements in as-grown epitaxial GaAs:C, but the possibility that there may have been effects due to the presence of a large concentration of hydrogen was not considered [7]. However, if $C_{i}$ atoms were mobile they could be trapped by $\mathrm{C}_{\mathrm{As}}$ atoms to form split-interstitial pairs $(C-C)_{[100]}$ aligned along a [100] direction $[8,9]$. Ab initio local density functional theory
(LDF) predicts that the defect is a deep donor and that $\left({ }^{12} \mathrm{C}-{ }^{12} \mathrm{C}\right)^{+}$pairs in AlAs give rise to a Raman active stretch mode at a frequency of $1590 \mathrm{~cm}^{-1}$ and an infrared (IR) active $E$ mode at $443 \mathrm{~cm}^{-1}$ [8]: we show that the corresponding frequencies for the analogous defect in GaAs are predicted to be 1798 and $329 \mathrm{~cm}^{-1}$. To date, only broad bands at 1355 and $1585 \mathrm{~cm}^{-1}$ have been observed in Raman spectra of annealed GaAs following ion implantation with ${ }^{12} \mathrm{C}[10]$. These features correspond to the $D$ and $G$ bands of $s p^{2}$ bonded graphitic carbon particles, and they shift to lower energies when samples are implanted with ${ }^{13} \mathrm{C}$, rather than ${ }^{12} \mathrm{C}$, confirming the proposed assignment.

We now report a study of carbon doped GaAs that received only thermal treatments to avoid possible complications arising from radiation damage [11]. The samples were grown at $540{ }^{\circ} \mathrm{C}$ by $\mathrm{CBE}$ using triethylgallium and cracked arsine and were doped with carbon $\left({ }^{12} \mathrm{C},{ }^{13} \mathrm{C}\right.$, or a mixture of ${ }^{12} \mathrm{C}$ and ${ }^{13} \mathrm{C}$ ) derived from ${ }^{12} \mathrm{CBr}_{4}$ and ${ }^{13} \mathrm{CBr}_{4}$ sources. Values of $p_{0}$ were determined from Hall effect measurements $(300 \mathrm{~K})$ and of $[\mathrm{C}]$ by secondary ion mass spectrometry (SIMS) (see Refs. [3,12]). Anneals, carried out in flowing gas $\left(10 \% \mathrm{H}_{2}\right.$ in Ar) with a faceto-face capping configuration using undoped $\mathrm{GaAs}$, were made at temperatures up to $850{ }^{\circ} \mathrm{C}$ for up to $4 \mathrm{~h}$. Raman measurements $(77 \mathrm{~K})$ were made in the backscattering geometry using excitation either from an $\mathrm{Ar}^{+}$ion laser $\left(h \nu_{L}=2.71 \mathrm{eV}\right)$ or from a $\mathrm{Kr}^{+}$ion laser $\left(h \nu_{L}=3.00\right.$ 
or $3.05 \mathrm{eV}$ ) [12]. The polarization of the incident light was either parallel or perpendicular to that of the detected light. The thicknesses of the epitaxial layers $(>300 \mathrm{~nm})$ were much greater than the probing depths in the Raman experiments of 20 and $10 \mathrm{~nm}$, respectively for the two lasers [12].

Raman measurements (2.71 eV excitation) made on a sample with $\left[{ }^{12} \mathrm{C}_{\mathrm{As}}\right]_{0}$ (Raman and SIMS) $\sim p_{0} \sim 2.5 \times$ $10^{20} \mathrm{~cm}^{-3}$ (Hall) showed reductions in the strength of the scattering from the ${ }^{13} \mathrm{C}_{\mathrm{As}}$ mode upon thermal annealing, corresponding to a $\sim 70 \%$ reduction in $\left[{ }^{13} \mathrm{C}_{\mathrm{As}}\right]$ using the established calibration for ${ }^{12} \mathrm{C}_{\text {As }}$ [13]. For optical excitation at $3.00 \mathrm{eV}$ (Fig. 1) no calibration is available but there is an inferred 90\% reduction in $\left[{ }^{13} \mathrm{C}_{\mathrm{As}}\right]$. As the probing depths for the two laser lines differ by a factor of 2, the Raman data could indicate a greater reduction of $\left[\mathrm{C}_{\mathrm{As}}\right]$ (after annealing) close to the surface. The final value of $\left[\mathrm{C}_{\mathrm{As}}\right]_{A}$ is the sum of the electrically compensated and uncompensated isolated acceptors since a change in the charge state from $\mathrm{C}_{\mathrm{As}}^{-}$to $\mathrm{C}_{\mathrm{As}}^{0}$ does not lead to a measurable shift in the localized vibrational mode (LVM) frequency [11]. The value of $\left[\mathrm{C}_{\mathrm{As}}\right]_{A}=8 \times 10^{19} \mathrm{~cm}^{-3}$ $\left(h \nu_{L}=2.71 \mathrm{eV}\right)$ was larger than $p_{A} \sim 3 \times 10^{19} \mathrm{~cm}^{-3}$ and so the concentration of hole traps that were introduced must have been $\sim 5 \times 10^{19} \mathrm{~cm}^{-3}$. We shall identify these traps with $\left[{ }^{13} \mathrm{C}-{ }^{13} \mathrm{C}\right]+$ defects present as single

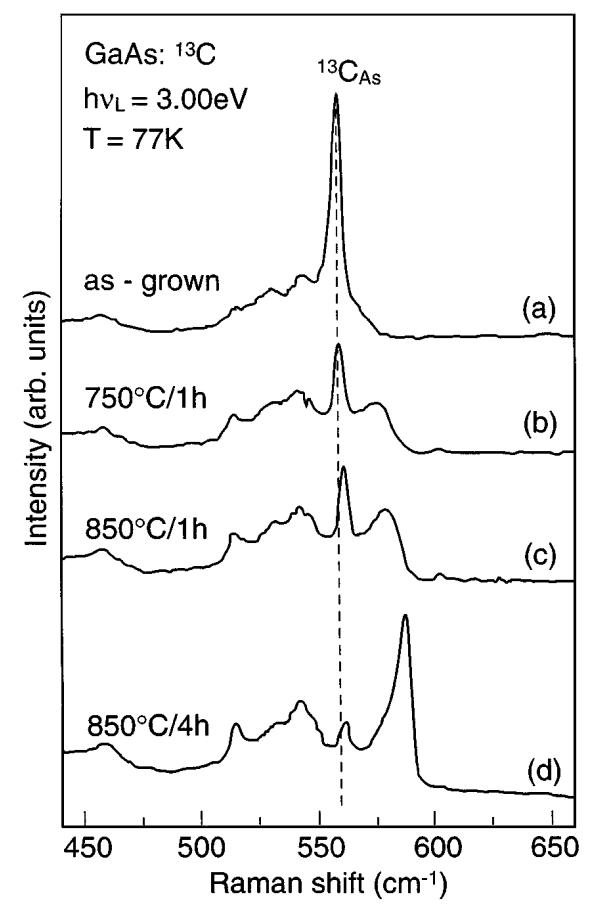

FIG. 1. Raman scattering (resolution $2.5 \mathrm{~cm}^{-1}$ ) from a sample with $\left[{ }^{13} \mathrm{C}_{\mathrm{As}}\right]_{0}=2.5 \times 10^{20} \mathrm{~cm}^{-3}$ showing reductions in $\left[{ }^{13} \mathrm{C}_{\mathrm{As}}\right]_{A}$ as a function of annealing treatments. Changes in the strength and position of the resonantly enhanced 2LO scattering are due to changes in $p$ and the improvement of the crystal perfection with increasing temperature (or time) of the anneal. deep donors involving $\sim 10^{20} \mathrm{~cm}^{-3}$ carbon atoms. It is implied that additional carbon atoms in a concentration of $\sim 7 \times 10^{19} \mathrm{~cm}^{-3}$ were present as electrically neutral complexes. Weak Raman scattering from the symmetric $A_{1}$ mode of $\mathrm{H}-\mathrm{C}_{\mathrm{As}}$ pairs was present in some as-grown samples [12], although it was usually, but not always, absent after the anneal $\left(\left[\mathrm{H}-\mathrm{C}_{\mathrm{As}}\right] \leq 3 \times 10^{18} \mathrm{~cm}^{-3}\right.$; detection limit $\leq 5 \times 10^{17} \mathrm{~cm}^{-3}$; measurements made on 4 samples). The loss of $\mathrm{C}_{\mathrm{As}}$ was therefore not due predominantly to the indiffusion of $\mathrm{H}$ atoms during the cooling period at the end of the anneal.

The most important new Raman results are shown in Fig. 2. In annealed $\left(825{ }^{\circ} \mathrm{C}, 3.5 \mathrm{~h}\right) \mathrm{GaAs}:{ }^{12} \mathrm{C}\left(p_{0}=\right.$ $\left.5 \times 10^{20} \mathrm{~cm}^{-3}\right)$, two lines are observed at 1742 and $1859 \mathrm{~cm}^{-1}$. In GaAs: ${ }^{13} \mathrm{C}\left(p_{0}=5 \times 10^{20} \mathrm{~cm}^{-2}\right)$, there are two corresponding lines at 1674 and $1788 \mathrm{~cm}^{-1}$, each isotopically shifted by a factor of 1.040 , close to $(13 / 12)^{1 / 2}=1.041$. These modes relate to $(\mathrm{C}-\mathrm{C}) \mathrm{di}$ carbon centers incorporating equivalent carbon atoms since two triplet structures are present, each with relative strengths close to $1: 2: 1$ in samples containing nearly equal concentrations of $\left[{ }^{12} \mathrm{C}\right]$ and $\left[{ }^{13} \mathrm{C}\right]$ of $1.0 \times 10^{20} \mathrm{~cm}^{-3}$ : modes from ${ }^{12} \mathrm{C}-{ }^{13} \mathrm{C}$ pairs occur at 1708 and $1824 \mathrm{~cm}^{-1}$ (Table I). All lines in the lower frequency group (T1)

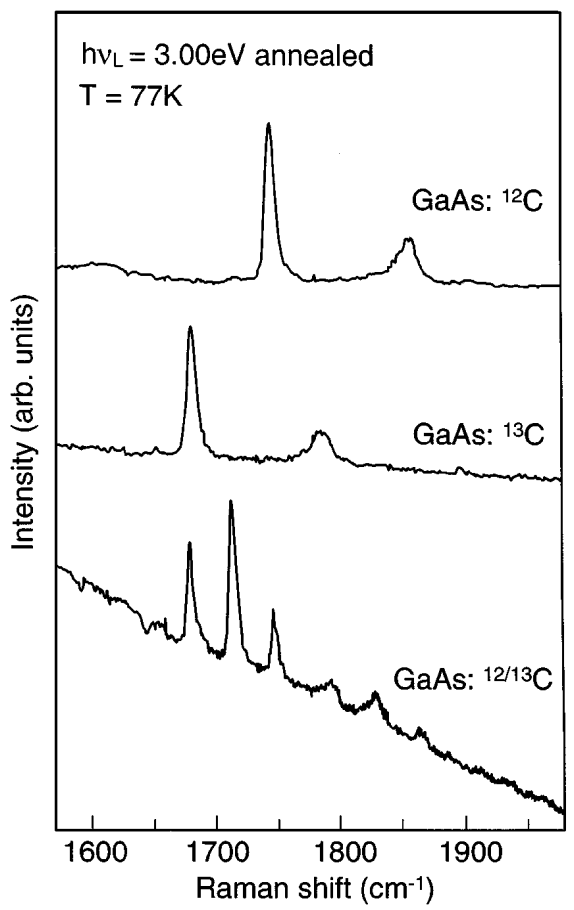

FIG. 2. Raman scattering (resolution $2 \mathrm{~cm}^{-1}$ ) from annealed samples that contained (a) $\left[{ }^{12} \mathrm{C}_{\mathrm{As}}\right]_{0}=5 \times 10^{20} \mathrm{~cm}^{-3}$, (b) $\left[{ }^{13} \mathrm{C}_{\mathrm{As}}\right]_{0}=5 \times 10^{20} \mathrm{~cm}^{-3}$, and (c) nearly equal concentrations of $\left[{ }^{12} \mathrm{C}_{\mathrm{As}}\right]_{0}=\left[{ }^{13} \mathrm{C}_{\mathrm{As}}\right]_{0}=1.0 \times 10^{20} \mathrm{~cm}^{-3}$ and with $p=2.5 \times 10^{20} \mathrm{~cm}^{-3}$. Samples (a) and (b) each show two lines, and there are isotopic shifts produced by changing ${ }^{12} \mathrm{C}$ to ${ }^{13} \mathrm{C}$. The triplet structures shown by sample (c) demonstrate that the defects are bonded (C-C) dicarbon defects (Table I). 
have full widths at half height $\Delta=8 \mathrm{~cm}^{-1}$ and those at the higher frequencies (T2) have $\Delta=17 \mathrm{~cm}^{-1}$. The modes have $A_{1}$ symmetry since the strength of the scattering is greater for parallel rather than crossed polarizations of the incident and scattered radiation [12]. We note that the frequency of the line from ${ }^{12} \mathrm{C}-{ }^{12} \mathrm{C}$ pairs at $1742 \mathrm{~cm}^{-1}$ is comparable with that of a double bonded $C=C$ structure that has a characteristic frequency of $1650 \mathrm{~cm}^{-1}$ in molecules [14].

Two of our samples doped with ${ }^{12} \mathrm{C}$ and ${ }^{13} \mathrm{C}$, respectively, showed broad bands at $\sim 1600$ and $1370 \mathrm{~cm}^{-1}$ due to $s p^{2}$-bonded clusters of ${ }^{12} \mathrm{C}[10]$. We attribute these bands to surface contamination because of the lack of an isotopic shift.

Since two Raman triplets are observed, it is necessary to consider whether one or two types of bonded (C-C) center are formed. The observations could relate to a single defect with a deep level (involving a highly localized electron) present in two charge states: alternatively, T2 might be due to the excitation of bonded (C-C) modes combined with carbon-induced resonances $\left(\sim 120 \mathrm{~cm}^{-1}\right)$ derived from the top of the transverse acoustic phonon band of GaAs, previously found for isoelectronic ${ }^{11} \mathrm{~B}_{\mathrm{Ga}}$ impurities at $123 \mathrm{~cm}^{-1}$ [15]. It is not known if carbon resonances exist as IR absorption measurements cannot be made because there is intense free-carrier absorption in this spectral region. However, this second possibility is considered unlikely as the strength of $\mathrm{T} 2$ is about $30 \%$ of that of $\mathrm{T} 1$ in all the annealed samples. The relative strengths of the two $\left({ }^{13} \mathrm{C}-{ }^{13} \mathrm{C}\right)$ lines were unchanged after wet etching was used to reduce the thickness of a ${ }^{13} \mathrm{C}$ doped layer by $50 \%$. Nevertheless, the two $\left({ }^{12} \mathrm{C}-{ }^{12} \mathrm{C}\right)$ modes observed in one as-grown ${ }^{12} \mathrm{C}$ sample had approximately equal strengths, rather than the 3:1 ratiothis observation may indicate that two distinct centers are present.

To study the effect of photo-generated carriers on the charge state of the scattering centers, the incident power density $\left(h \nu_{L}=3.00 \mathrm{eV}\right.$ : laser power on the sample $150 \mathrm{~mW}$, focused spot $70 \mu \mathrm{m}$ in diameter) was reduced by a factor of 3 . This resulted in a reduction in the intensity of the $1742 \mathrm{~cm}^{-1}\left({ }^{12} \mathrm{C}-{ }^{12} \mathrm{C}\right)$ mode (T1: Table I) by a factor of 1.9: the corresponding reduction in the $1859 \mathrm{~cm}^{-1}$ (T2) line was 2.3. The scattering from both modes changes sublinearly with excitation power, indicating that photo-generated carriers may have some effect on the charge state and hence on the apparent concentrations of the scattering centers.

Spectra were then recorded for the sample doped with ${ }^{12} \mathrm{C}$ using laser energies of 2.71, 3.00, or $3.05 \mathrm{eV}$ (Fig. 3). The lines at $1859 \mathrm{~cm}^{-1}\left(1788 \mathrm{~cm}^{-1}\right)$ from ${ }^{12} \mathrm{C}\left({ }^{13} \mathrm{C}\right)(\mathrm{T} 2)$ show strong resonant enhancements when $h \nu_{L}$ is close to the $E_{1}$ gap of $\mathrm{GaAs}$ of $\sim 3.00 \mathrm{eV}$ (see Ref. [16]). The nonresonant behavior of the line from T1 at $1742 \mathrm{~cm}^{-1}$ $\left(1674 \mathrm{~cm}^{-1}\right)$ provides evidence that two complexes with different electronic levels are present, only one of which
TABLE I. Experimental and calculated LVM frequencies and calculated lengths $B(\AA)$ of the C-C bonds of dicarbon complexes in GaAs.

\begin{tabular}{|c|c|c|c|c|}
\hline \multirow[b]{2}{*}{ (C-C) Defect } & \multicolumn{3}{|c|}{ Triplet frequencies $\left(\mathrm{cm}^{-1}\right)$} & \multirow{2}{*}{$\begin{array}{c}\mathrm{B}(\AA) \\
\mathrm{C}-\mathrm{C}\end{array}$} \\
\hline & ${ }^{12} \mathrm{C}-{ }^{12} \mathrm{C}$ & ${ }^{12} \mathrm{C}-{ }^{13} \mathrm{C}$ & ${ }^{13} \mathrm{C}-{ }^{13} \mathrm{C}$ & \\
\hline Expt.:T1 & 1742 & 1708 & 1674 & \\
\hline Expt.:T2 & 1859 & 1824 & 1788 & \\
\hline $\mathrm{LPF}^{\mathrm{a}}(\mathrm{C}-\mathrm{C})_{[100]}^{+}$ & 1798 & 1764 & 1728 & 1.24 \\
\hline $\operatorname{LPF}^{\mathrm{a}}(\mathrm{C}-\mathrm{C})_{[100]}^{0}$ & 1507 & 1478 & 1448 & 1.31 \\
\hline LDF (As cage $)^{0}$ & 1887 & 1850 & 1813 & 1.23 \\
\hline $\mathrm{LDF}(\mathrm{Ga} \text { cage })^{0}$ & 1657 & 1624 & 1592 & 1.26 \\
\hline
\end{tabular}

${ }^{\mathrm{a}}(\mathrm{C}-\mathrm{C})_{[100]}$ center in As lattice site with ${ }^{69} \mathrm{Ga}$ neighbors: shifts on replacing ${ }^{69} \mathrm{Ga}$ by ${ }^{71} \mathrm{Ga}$ less than $0.002 \mathrm{~cm}^{-1} ; E$ modes predicted at $\sim 320$ and $417 \mathrm{~cm}^{-1}$ for the positive and neutral charge states, respectively, are not observed by Raman scattering or by IR absorption.

could be a $(\mathrm{C}-\mathrm{C})_{[100]}$ split interstital. Two further weak lines at $1152 \mathrm{~cm}^{-1}\left({ }^{12} \mathrm{C}\right.$ ) and $1120 \mathrm{~cm}^{-1}\left({ }^{13} \mathrm{C}\right)$ (not shown) were only detected for excitation with $h \nu_{L} \sim$ $3.0 \mathrm{eV}$ but were not observed in the mixed isotope sample. The frequency ratio of these lines (1.028) is significantly smaller than that for a full carbon isotopic shift (1.041), and assignments of these lines are unknown.

The structure and vibrational frequencies of the $(\mathrm{C}-\mathrm{C})_{[100]}$ complex in GaAs were calculated by ab initio LDF theory (see Refs. $[8,17]$ ) for both its positive and

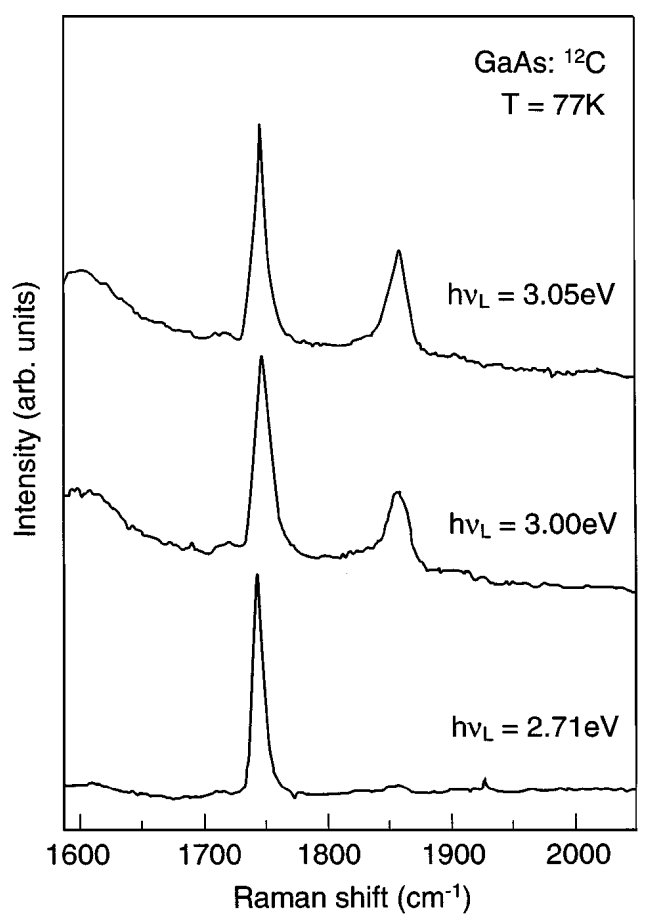

FIG. 3. Raman spectra of an annealed $\left(850{ }^{\circ} \mathrm{C}\right) \mathrm{GaAs}:{ }^{12} \mathrm{C}$ sample showing resonant enhancement for $h \nu_{L} \sim 3.0 \mathrm{eV}$ (resolution $6 \mathrm{~cm}^{-1}$ ) of the line at $1859 \mathrm{~cm}^{-1}$ but not for that at $1742 \mathrm{~cm}^{-1}$ (Table I, Fig. 2). 
neutral charge states (Table I). The calculated frequencies for $(\mathrm{C}-\mathrm{C})_{[100]}^{+}$are in good agreement with those measured for $\mathrm{T} 1$, but the calculated decrease in the frequencies for $(\mathrm{C}-\mathrm{C})_{[100]}^{0}$ is inconsistent with an assignment to T2 that occurs at a higher frequency than T1. The reason for the calculated decrease is that the highest occupied electronic state is an antibonding $\pi$-like pair of orbitals forming $E$ states so that electron density is removed from the C-C bond. Alternatively, the modes of T2 might be explained according to preliminary calculations by a neutral [100] oriented (C-C) pair that occupies a tetrahedral interstitial As cage and could be a deep acceptor. A similar (C-C) pair occupying a $\mathrm{Ga}$ cage is a donor, but the properties of other complexes such as a pair of dimers occupying second neighbor As sites have not been investigated.

In conclusion, anneals of $\mathrm{CBE}$ GaAs: $\mathrm{C}_{\mathrm{As}}$ layers lead to the loss of isolated $\mathrm{C}_{\mathrm{As}}$ acceptors and the formation of dicarbon $\mathrm{C}-\mathrm{C}$ complexes, identified by high frequency Raman active modes from crystals containing ${ }^{12} \mathrm{C}$ and ${ }^{13} \mathrm{C}$. Ab initio calculations predict vibrational frequencies for the positively charged split-interstitial defect occupying an As lattice site $(\mathrm{C}-\mathrm{C})_{[100]}^{+}$that are close to those of the lower frequency $\mathrm{T} 1$ : Frequencies predicted for $(\mathrm{C}-\mathrm{C})_{[100]}^{0}$ are not consistent with those for T2 that might be due to a $(\mathrm{C}-\mathrm{C})^{0}$ pair in an interstitial site with As nearest neighbors. The assignments of the two triplets to a single donor and a neutral defect, respectively, are consistent with our analysis relating to the loss of $\mathrm{C}_{\mathrm{As}}$ acceptors. These measurements imply transfer of $\mathrm{C}_{\mathrm{As}}$ atoms to interstitial sites and the capture of these atoms by undisplaced $\mathrm{C}_{\mathrm{As}}$ atoms and possibly the formation of bonded diinterstitials. These processes indicate mechanisms for the loss of free carriers in annealed highly carbon doped GaAs.

J.W thanks P. Koidl for continuing support, while The Engineering and Physical Sciences Research Council (EPSRC), United Kingdom, are thanked for their financial support by R. C. N. and B. R. D. (Grant No. GR/K96977), S. P. W., T. J. B., and J. B. J. (Grant No. GR/J77436), and C. D. L. and R. J. (Grant No. GR/K05528). S.P. W. also thanks The EPSRC for the provision of a research studentship. S.O. thanks NFR and TFR Sweden for financial support and PDC (Sweden) for computer time on the SP2.
[1] C. R. Abernathy, in State-of-the-Art Program on Compound Semiconductors XXIV, edited by F. Ren, S.J. Pearton, S. N. G. Chu, R. J. Shul, W. Pletschen, and T. Kamijo (The Electrochem. Soc., Pennington, NJ, 1996), Vol. 96-2, pp. 1-18.

[2] T. J. de Lyon, N. I. Buchan, P. D. Kirchner, J. M. Woodall, G. J. Scilla, and F. Cardone, Appl. Phys. Lett. 58, 517 (1991).

[3] B. R. Davidson, R.C. Newman, T.J. Bullough, and T. B. Joyce, Phys. Rev. B 45, 17,106 (1993).

[4] K. Woodhouse, R. C. Newman, T.J. de Lyon, J. M. Woodall, G. J. Scilla, and F. Cardone, Semicond. Sci. Technol. 6, 330 (1991).

[5] L. Hart, B. R. Davidson, J. M. Fernández, R. C. Newman, and C. C. Button, Mater. Sci. Forum 196-201, 409 (1995).

[6] S. P. Westwater and T. J. Bullough, J. Crys. Growth (to be published).

[7] G. E. Höfler and K. C. Hsieh, Appl. Phys. Lett. 61, 327 (1992).

[8] R. Jones and S. Öberg, Mater. Sci. Forum 143-147, 253 (1994).

[9] B. H. Cheong and K. J. Chang, Phys. Rev. B 49, 17436 (1994).

[10] A. J. Moll, E.E. Haller, J.W. Ager III, and W. Walukiewicz, Appl. Phys. Lett. 65, 1145 (1994); A. J. Moll, J. W. Ager III, Kin Man Yu, W. Walukiewicz, and E. E. Haller, IOP Conf. Ser. 141, 269 (1995).

[11] R. C. Newman, in Imperfections in III-V Materials, edited by R.W. Willardson, A.C. Beer, and E. R. Weber, Semiconductors and Semimetals Vol. 38 (Academic, San Diego, CA, 1993), pp. 117-187.

[12] J. Wagner, K. H. Bachem, B. R. Davidson, R. C. Newman, T. J. Bullough, and T.B. Joyce, Phys. Rev. B 51, 4150 (1995).

[13] J. Wagner, M. Maier, Th. Lauterbach, K. H. Bachem, A. Fischer, K. Ploog, G. Moersch, and M. Kamp, Phys. Rev. B 45, 9120 (1992).

[14] G. Herzberg, Molecular Spectra and Molecular Structure II . Infrared and Raman Spectra of Polyatonmic Molecules (Van Nostrand Rheinhold, New York, 1957), 5th Ed., p. 195.

[15] J. F. Angress, G. A. Gledhill, and R. C. Newman, J. Phys. Chem. Solids 41, 341 (1980).

[16] J. Wagner, P. Koidl, and R. C. Newman, Appl. Phys. Lett. 59, 1729 (1991).

[17] R. Jones, Philos. Trans. R. Soc. London A 341, 351 (1992). 